\title{
Geochemical influences on nonenzymatic oligomerization of prebiotically relevant cyclic nucleotides
}

\author{
SHIKHA DAGAR, SUSOVAN SARKAR, and SUDHA RAJAMANI \\ Department of Biology, Indian Institute of Science Education and Research, Pune 411008, India
}

\begin{abstract}
The spontaneous emergence of long RNA molecules on the early Earth, a phenomenon central to the RNA World hypothesis, continues to remain an enigma in the field of origins of life. Few studies have looked at the nonenzymatic oligomerization of cyclic mononucleotides under neutral to alkaline conditions, albeit in fully dehydrated state. In this study, we systematically investigated the oligomerization of cyclic nucleotides under prebiotically relevant conditions, wherein starting reactants were subjected to repeated dehydration-rehydration (DH-RH) regimes. DH-RH conditions, a recurring geological theme that was prevalent on prebiotic Earth, are driven by naturally occurring processes including diurnal cycles and tidal pool activity. These conditions have been shown to facilitate uphill oligomerization reactions. The polymerization of $2^{\prime}-3^{\prime}$ and $3^{\prime}-5^{\prime}$ cyclic nucleotides of a purine (adenosine) and a pyrimidine (cytidine) was investigated. Additionally, the effect of amphiphiles was also evaluated. Furthermore, to discern the effect of "realistic" conditions on this process, the reactions were also performed using a hot spring water sample from a candidate early Earth environment. Our study showed that the oligomerization of cyclic nucleotides under $\mathrm{DH}-\mathrm{RH}$ conditions resulted in intact informational oligomers. Amphiphiles increased the stability of both the starting monomers and the resultant oligomers in selected reactions. In the hot spring reactions, both the oligomerization of nucleotides and the back hydrolysis of the resultant oligomers were pronounced. Altogether, this study demonstrates how nonenzymatic oligomerization of cyclic nucleotides, under both laboratory-simulated prebiotic conditions and in a candidate early Earth environment, could have resulted in RNA oligomers of a putative RNA World.
\end{abstract}

Keywords: dehydration-rehydration cycles; lipid-assisted oligomerization; cyclic nucleotides; candidate prebiotic environments; hot springs

\section{INTRODUCTION}

The "RNA World hypothesis" emphasizes the potential of RNA molecules to be the first biomolecule to have emerged on the prebiotic Earth due to its capability to act as a catalyst, in addition to being able to encode genetic information (Gilbert 1986). The presence of complex protein machineries that could have assisted in the process of encoding and processing of genetic information would have been highly improbable on the early Earth. Therefore, the formation and replication of RNA molecules on prebiotic Earth would have been nonenzymatic; driven by the environmental conditions and the physio-chemical properties of the molecules, resulting in oligonucleotides. Small oligoribonucleotides (up to trimers) have been shown to not only enhance the rate of template-directed replication (Kaiser and Richert 2013; Li et al. 2017; Tam et al. 2017; O'Flaherty et al. 2018), but are also thought

Corresponding author: srajamani@iiserpune.ac.in

Article is online at http://www.rnajournal.org/cgi/doi/10.1261/rna. 074302.119 . to act as precursors for cofactors that pervade extant biology (Puthenvedu et al. 2015, 2018; Majerfeld et al. 2016).

Previous studies that have looked at the oligomerization and replication of RNA molecules under prebiotic conditions have typically used chemically modified nucleotides such as imidazole-activated nucleotides as the starting monomers (Lohrmann and Orgel 1973; Blain and Szostak 2014; Puthenvedu et al. 2015, 2018; Majerfeld et al. 2016). Though a recent study has demonstrated the synthesis of such imidazole-activated nucleotides under prebiotic conditions ( $\mathrm{Yi}$ et al. 2018), their availability in significant amounts is still uncertain. Furthermore, the unstable nature of these activated nucleotides toward high temperatures and aqueous conditions make their potential role as substrates for enzyme-free oligomerization highly debatable. The lipid-assisted nonenzymatic

(C) 2020 Dagar et al. This article is distributed exclusively by the RNA Society for the first 12 months after the full-issue publication date (see http://rnajournal.cshlp.org/site/misc/terms.xhtml). After 12 months, it is available under a Creative Commons License (Attribution-NonCommercial 4.0 International), as described at http:// creativecommons.org/licenses/by-nc/4.0/. 
oligomerization of nucleoside $5^{\prime}$-monophosphates (NMP) has also been demonstrated under terrestrial acidic geothermal conditions (Rajamani et al. 2008).

However, systematic characterization of these products showed the formation of RNA-like polymers with abasic sites (Mungi et al. 2015) due to the loss of the informational moiety under the aforesaid conditions. Hence, it is disputable that the resultant moieties that formed under such conditions would have been capable of functioning as informational oligomers. Conversely, cyclic nucleotides can readily form under prebiotic conditions and are stable to high temperatures while being intrinsically active (Tapiero and Nagyvary 1971; Verlander et al. 1973; Verlander and Orgel 1974; Costanzo et al. 2007; Powner et al. 2009, 2010; Saladino et al. 2012; Suárez-Marina et al. 2019). Therefore, they could have potentially served as monomers for enzyme-free oligomerization reactions that result in RNA. Toward this, Verlander et al. (1973) demonstrated the nonenzymatic oligomerization of $2^{\prime}-3^{\prime}$ cyclic nucleoside monophosphates (cNMPs) under completely dry conditions. Subsequent studies from di Mauro's group have showed the formation of RNA oligomers up to tetramers using $3^{\prime}-5^{\prime}$ cyclic nucleotides under slightly alkaline regimes and in dry conditions (Costanzo et al. 2012, 2016). Although insightful, an important aspect pertaining to these studies is the uncertainty of the existence of permanently dry niches on the early Earth. The realistic approach would then be to consider these reactions in niches that have been hypothesized to support the chemical emergence of life. One of these proposed niches is that of terrestrial hydrothermal pools. Temperature and seasonal fluctuations in these terrestrial pools would result in dry-wet cycles (Dehydration-Rehydration/DH-RH cycles) (Higgs 2016; Ross and Deamer 2016), a feature common to the geology of the planet to this day. Such DH-RH cycles have been demonstrated to facilitate the formation of a diverse set of RNA building blocks (purine nucleosides) (Becker et al. 2018, 2019), and also in the condensation of hydroxy acids, either alone or in combination with amino acids, to result in oligoesters and depsipeptides, respectively (Mamajanov et al. 2014; Forsythe et al. 2015). As mentioned earlier, lipids have been shown to facilitate the oligomerization of $5^{\prime}-\mathrm{NMPs}$ under $\mathrm{DH}-\mathrm{RH}$ conditions, resulting in the formation of RNA-like oligomers (abasic oligomers) (Rajamani et al. 2008; Mungi et al. 2015). Upon dehydration lipid molecules arrange themselves into two-dimensional arrays, concentrating the reacting monomers thereby promote concentration-dependent oligomerization. Upon rehydration, the multilamellar structures can encapsulate the monomers, as well as the growing oligomers, forming protocell-like entities, thus protecting them from hydrolysis (Toppozini et al. 2013; Damer and Deamer 2015). The Influence of lipids on nonenzymatic oligomerization of cyclic nucleotides has not been explored to our knowledge.
Additionally, most of the previous studies that have been undertaken to demonstrate the nonenzymatic oligomerization of cyclic nucleotides have used purines as the starting monomer (Verlander et al. 1973; Verlander and Orgel 1974; Pino et al. 2008; Costanzo et al. 2016). Very few studies have looked at the oligomerization of pyrimidines under dry conditions (Tapiero and Nagyvary 1971; Costanzo et al. 2017). Purines are known for their tendency to stack better than pyrimidines. This increases the proximity of these nucleotides thereby facilitating intermolecular condensation leading to their efficient oligomerization (Giovanna et al. 2009). Given this, we aimed to elucidate whether there is any effect from the aforesaid difference (between purine and pyrimidine) on the oligomerization efficiency under our reaction conditions. Furthermore, we also wanted to discern the role of lipid molecules on the oligomerization of cyclic nucleotides under prebiotically pertinent $\mathrm{DH}-\mathrm{RH}$ regimes. Toward this, enzyme-free oligomerization of cyclic nucleotides was studied using cyclic adenosine monophosphate (cAMP), a purine, and cyclic cytosine monophosphate (cCMP), a pyrimidine nucleotide, using both the $2^{\prime}-3^{\prime}$ and $3^{\prime}-5^{\prime}$ cyclic isomer versions.

Lastly, the studies pertaining to nucleotide oligomerization are predominantly carried out under laboratory-controlled conditions. Although insightful, such controlled reactions may not be representative of the complex scenarios that might have been present on the early Earth. Toward this, few studies have begun to evaluate prebiotic processes under more "realistic" conditions. For example, Deamer et al. (2006) tried to constrain the range of possible environments/conditions for the origins of life by analyzing prebiotically pertinent processes under realistic conditions. The previous study from our laboratory looked at the self-assembly of simple amphiphiles, like fatty acids and their derivatives, in alkaline hot spring water samples of varying ionic content that were collected from three locations in Ladakh, a candidate site with early Earth-like environmental niches (Joshi et al. 2017). However, to our knowledge, similar studies have not been undertaken in the context of nonenzymatic oligomerization of nucleotides, under candidate prebiotic early Earth environments. Therefore, we also set out to investigate how cyclic nucleotide oligomerization reactions would advent in a complex "realistic" context. We evaluated this by using a hot spring sample that was used in the previous study (Joshi et al. 2017), and studied it alongside reactions carried out under laboratory-controlled conditions. Under the laboratorysimulated conditions, intact oligomers up to trimers (in the pyrimidine reactions) and tetramers (in the purine reactions) were observed in some of the oligomerization reactions. Interestingly, in the reactions performed using the hot spring water sample, not only the rate of oligomerization, but also the destabilization of the oligomers was enhanced over prolonged cycles. 


\section{RESULTS}

\section{Nonenzymatic oligomerization of cyclic adenosine monophosphate under $\mathrm{DH}-\mathrm{RH}$ conditions}

We investigated the enzyme-free oligomerization of cyclic nucleotides under laboratory-simulated $\mathrm{DH}-\mathrm{RH}$ regimes. A typical reaction involved $5 \mathrm{mM}$ of the corresponding cyclic nucleotides $\left(2^{\prime}-3^{\prime}\right.$ or $3^{\prime}-5^{\prime}$ cAMP) at $\mathrm{pH}$ 8 , which were subjected to $30 \mathrm{DH}-$ $\mathrm{RH}$ cycles (at $24 \mathrm{~h}$ per cycle) (Methods). A dry heating control reaction was also set up under identical temperature, $\mathrm{pH}$ and reactant concentrations, wherein the sample was only subjected to prolonged drying without any rehydration involved. This was also done to recreate conditions used in previous studies (Verlander and Orgel 1974; Verlander et al. 1973; Costanzo et al. 2012, 2016). The reactions were analyzed using high-performance liquid chromatography (HPLC) (Methods). The product identities were ascertained by coeluting them on HPLC with known controls. The control species including CAMP, AMP monomer, dimer, and trimer, showed peaks eluting at $1.8,6.1,6.3$, and $7.1 \mathrm{~min}$, respectively. The peak observed with a retention time of $1.5 \mathrm{~min}$ is adenine, which is mentioned as a breakdown peak in the chromatogram (Fig. 1A). Free adenine does not interact with an anion-exchange column like the one that was used for this analysis, and elutes out of the column in the void volume.

As shown in the HPLC chromatogram (Fig. 1B), the reaction mixture kept at $90^{\circ} \mathrm{C}$ for $30 \mathrm{~d}$ under complete dry heating conditions led to the hydrolysis of cAMP to its linear form (i.e., AMP), however, no oligomers were observed for both of the cyclic isomers $\left(2^{\prime}, 3^{\prime}\right.$ cAMP and $3^{\prime}, 5^{\prime}$ cAMP) (Fig. 1B,D). Conversely, under DH-RH conditions, a peak, which had identical retention time as that of the control dimer, was observed in the 2', 3' cAMP oligomerization reaction (Fig. 1A). Nonetheless, there was no clear separation observed among the other peaks with a retention time more than that of AMP in the HPLC chromatogram. This could be, both, due to the relatively low yields of the reaction, and due to the presence of different types of product species. For example, the resultant products could be either cyclic or linear versions, and could also have varied internucleotide linkages, especially in the $2^{\prime}, 3^{\prime}$ cNMP reactions (Fig. 2). However, in the case of $3^{\prime}, 5^{\prime}$ cAMP reactions under $\mathrm{DH}-\mathrm{RH}$ conditions, oligomeric species was not detected using HPLC (Fig. 1C). All the reactions were performed at least in replicate to validate the results. Additionally, an aqueous heating control was also set up under identical conditions without invoking dry phase and was monitored for $120 \mathrm{~h}$. The stability of $2^{\prime}, 3^{\prime}$ cAMP was compromised under such conditions and only breakdown (adenine) and AMP peaks were observed (48.28\% of cAMP was remaining after $120 \mathrm{~h}$ of aqueous heating; Fig. 3 ).

Time of flight-mass spectrometry (TOF-MS) analysis was performed in order to further confirm and characterize the various species that were formed under $\mathrm{DH}-\mathrm{RH}$ conditions and observed in the HPLC chromatograms (Methods). Fragmentation was induced for the precursor molecule using the TOF-MS/MS mode. Figure 4 shows representative TOF-MS and TOF-MS/MS spectra that were observed in electro spray ionization (ESI) positive mode for $\mathrm{H}^{+}$adducts of AMP linear dimer (panels A and B), along with its corresponding structure (panel C), AMP linear trimer (panels D and $\mathrm{E}$ ), and its corresponding structure (panel F), and 


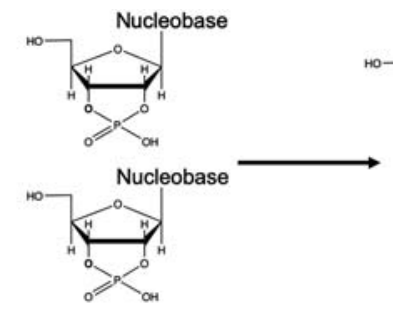

2'-3' cyclic nucleotide
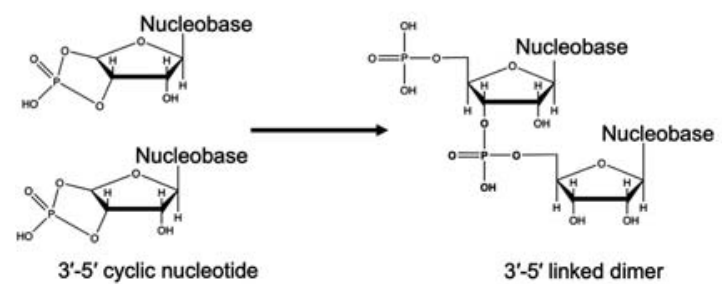

$3^{\prime}-5^{\prime}$ linked dimer

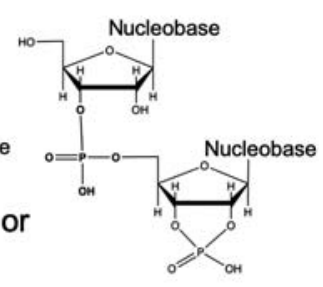

3'-5'-linked cyclic dimer

FIGURE 2. Schematic showing possible phosphodiester linked products resulting in the oligomerization reactions of 2', 3' cyclic nucleotides and 3', 5' cyclic nucleotides. Schematic made using ChemDraw Professional, version 19.0.0.26.

AMP linear tetramer (panels $\mathrm{G}$ and $\mathrm{H}$ ), and its corresponding structure (panel I). All the observed masses have been summarized in Table 1, with the errors being well within the acceptable range (give or take $[ \pm] 5$ parts per million [ppm]). The fragmentation of AMP linear dimer with a monoisotopic mass of 677.123 Da yielded an intense fragment at $348.067 \mathrm{Da}$, and another fragment at $542.064 \mathrm{Da}$ (Fig. 4A,B). AMP linear trimer with a monoisotopic mass of 1006.170 fragmented into two intense fragments of 348.067 Da, and 677.112 Da (Fig. 4D,E). AMP linear tetramer with a monoisotopic mass of 1335.238 fragmented into two intense fragments of $348.074 \mathrm{Da}$, and 677.12 Da (Fig. 4G,H). The fragmentation fingerprint of the parent molecule, its ppm accuracy, and the elution time were all used in conjunction to confirm the presence of the target molecules. The TOF-MS spectrum for the $2^{\prime}, 3^{\prime}$ cAMP reaction showed the presence of intact linear dimer within four $\mathrm{DH}-\mathrm{RH}$ cycles, and intact linear trimer and tetramer after 10 DH-RH cycles (Fig. 8; Table 4). However, 3', 5' cAMP yielded only an intact linear dimer even after $20 \mathrm{DH}-\mathrm{RH}$ cycles. This lower oligomerization propensity of 3', 5' cAMP (oligomers only up to dimer as compared to tetramer in the case of $2^{\prime}, 3^{\prime}$ cAMP) could possibly stem from its higher intrinsic stability. More than $90 \%$ of the starting monomer typically remained even after $30 \mathrm{DH}-\mathrm{RH}$ cycles and this could possibly be due to comparatively less ring strain in its six-membered ring $(8.9 \mathrm{kcal} / \mathrm{mol})$ than the five-membered ring $(12$ $\mathrm{kcal} / \mathrm{mol}$ ) of 2', 3' cAMP (Khorana et al. 1957).

\section{Nonenzymatic oligomerization of cyclic cytosine monophosphate under $\mathrm{DH}-\mathrm{RH}$ conditions}

In order to compare the oligomerization potential of purine versus pyrimidine cyclic nucleotides, reactions were

carried out using cCMP. The reactant concentrations and reaction conditions including $\mathrm{DH}-\mathrm{RH}$ cycling at $90^{\circ}$ $\mathrm{C}$ (30 DH-RH cycles with $24 \mathrm{~h}$ per cycle), were kept identical to what was used in the CAMP reactions. Both of the cyclic isomers, that is, 2', $3^{\prime}$-cCMP and $3^{\prime}, 5^{\prime}$-cCMP were investigated for their nonenzymatic oligomerization potential. Mass analysis of the cCMP oligomerization reaction products was performed and the parameters for TOF-MS and TOF-MS/ MS were kept identical to that of the cAMP reactions (Methods). Figure 5 shows a representative TOF-MS spectra and TOF-MS/MS spectra in ESI positive mode that were observed for the $\mathrm{H}^{+}$adduct of CMP linear dimer (panels $\mathrm{A}$ and $\mathrm{B}$ ), along with its corresponding structure (panel $\mathrm{C}$ ), and $\mathrm{H}^{+}$adduct of $\mathrm{CMP}$ linear trimer (panels $\mathrm{D}$ and $\mathrm{E}$ ) and its corresponding structure (panel F). As seen in Figure 5, the CMP linear dimer with a monoisotopic mass of $629.099 \mathrm{Da}$ fragmented into daughter fragments with masses 611.087, 306.046, and $518.063 \mathrm{Da}$. CMP linear trimer with a monoisotopic mass of 934.142 fragmented into $306.047 \mathrm{Da}$, and 629.096 $\mathrm{Da}$, respectively. All the observed masses with their respective ppm errors are summarized in Table 1. The TOF-MS and MS/MS analysis for the 2', 3' cCMP and 3', $5^{\prime}$ cCMP reactions show the presence of linear trimer and linear dimer, respectively, within $10 \mathrm{DH}-\mathrm{RH}$ cycles (Fig. $8 \mathrm{~B})$. The lower extent of oligomerization for cCMP than CAMP (oligomers only up to trimer as compared to tetramer), could potentially be due to the intrinsically higher stability of CCMP toward the hydrolysis of intramolecular

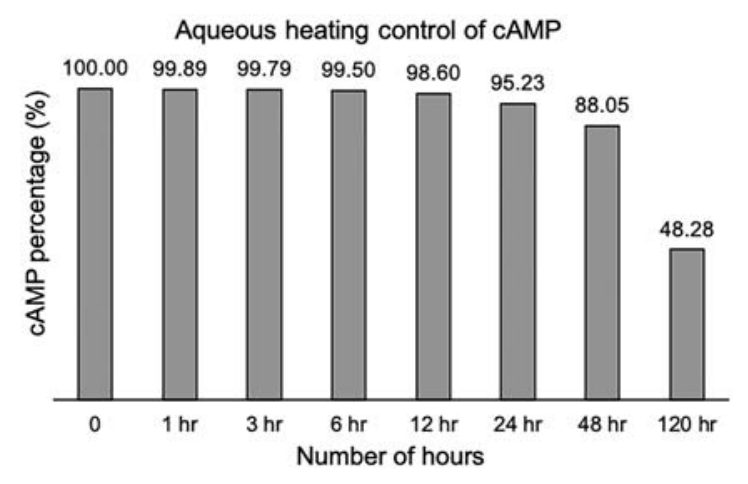

FIGURE 3. The stability of cAMP under aqueous heating. The graph shows the stability of the starting monomer (after accounting for both $2^{\prime}, 3^{\prime}$ cAMP and AMP as they can readily interchange in aqueous conditions). $X$-axis shows different time periods (in hours) after which samples were withdrawn and analyzed using HPLC. Y-axis shows percent cAMP remaining, normalized to the amount present in cycle zero. 

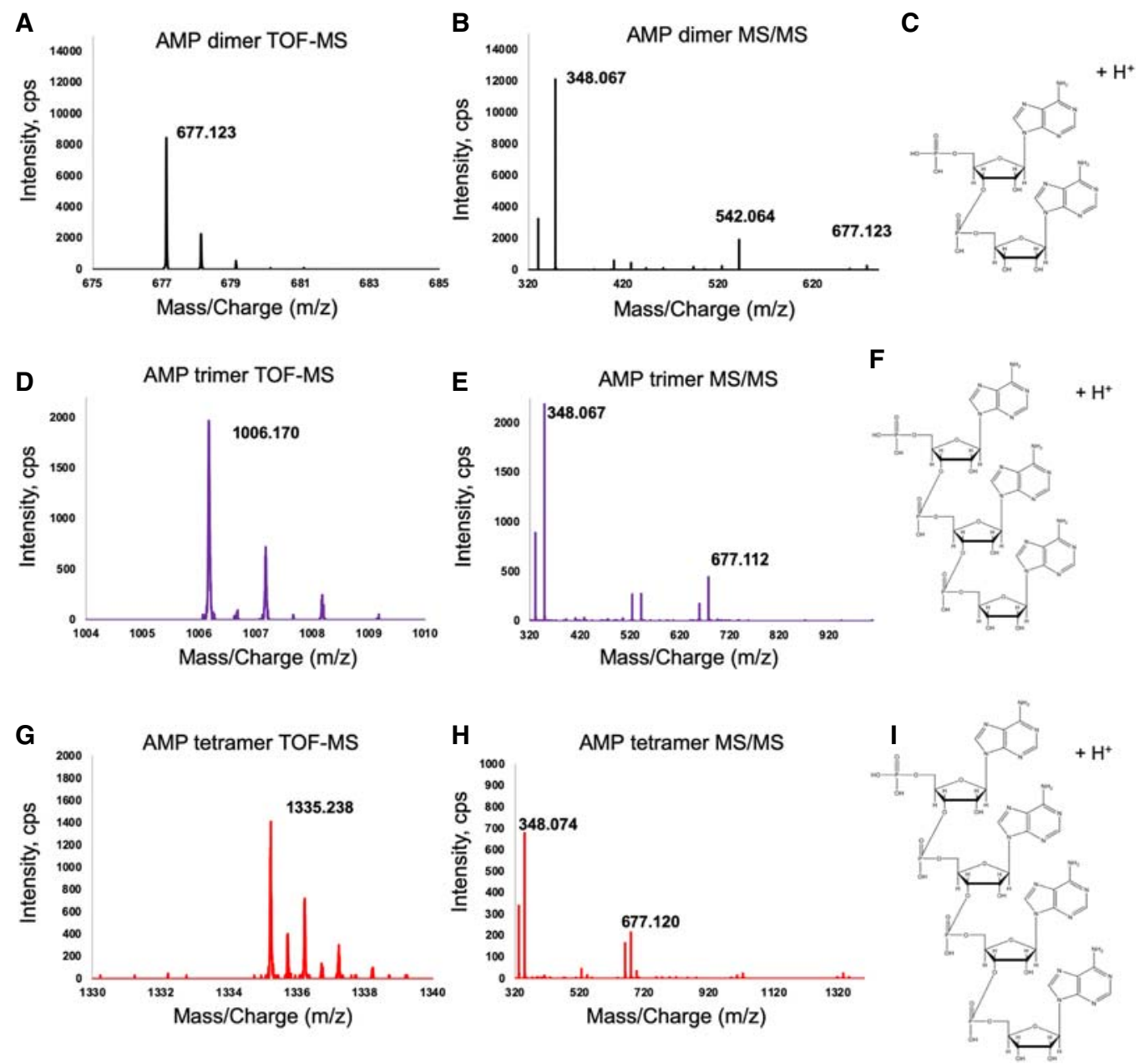

FIGURE 4. Representative TOF-MS and TOF-MS/MS spectra in ESI positive mode for cAMP reactions. From left to right: the TOF-MS spectrum, TOF-MS/MS spectrum, and the representative structure of different AMP oligomer species observed. The species correspond to $\mathrm{H}^{+}$adducts of AMP linear dimer $(A-C)$ with a monoisotopic mass of 677.12 Da, AMP linear trimer ( $D-F)$ with a monoisotopic mass of 1006.17 Da, and AMP linear tetramer (G-I) with a monoisotopic mass of $1335.23 \mathrm{Da}$, respectively.

phosphodiester linkage $\left(\Delta H_{\text {hydrolysis }}=-8.1 \mathrm{kcal} / \mathrm{mol}\right.$ for $\mathrm{cCMP}$ and $\Delta H_{\text {hydrolysis }}=-9.4 \mathrm{kcal} / \mathrm{mol}$ for cAMP, both at $\left.\mathrm{pH} 7.3,25^{\circ} \mathrm{C}\right)$ (Gerlt et al. 1974).

\section{Effect of lipids on the stability of cyclic nucleotides under DH-RH conditions}

Lipids have been demonstrated to encapsulate macromolecules under DH-RH cycles (Deamer and Barchfeld 1982). They are also known to interact better with certain molecules present in the bulk solution (Black et al. 2013; Sasidharan et al. 2019), consequently protecting them from the harsh environmental conditions of an early Earth. In the context of nucleotide oligomerization reactions, lipids have been shown to also facilitate the formation of RNA-like polymers (abasic oligomers) from nucleoside-5' monophosphates (Rajamani et al. 2008; Mungi et al. 2015). Given this, we set out to elucidate the plausible effect of lipids on the enzyme-free oligomerization of CNMP (CAMP and CCMP based reactions). The reactions were performed in the presence of 1-palmitoyl, 2-oleoyl phosphatidylcholine (POPC), a phospholipid that has been used as a proxy membrane component in several previous studies (Chen et al. 2005; Rajamani et al. 2008; Chen and Walde 2010; DeGuzman et al. 2014; Mungi et al. 2015). A total of $1 \mathrm{mM}$ of POPC was added to each reaction containing $5 \mathrm{mM}$ of cNMP to maintain a constant ratio of 5:1 of nucleotide to lipid. The reaction conditions and subsequent procedures were kept identical to those mentioned in the previous section $\left(90^{\circ} \mathrm{C}, 30 \mathrm{DH}-\mathrm{RH}\right.$ cycles with $24 \mathrm{~h}$ per cycle) (Methods). In order to get an estimate of the amount of starting monomer in the HPLC runs, the areas under both linear NMP and CNMP peaks were taken into consideration, as cNMP can readily convert to NMP under aqueous conditions (Suárez-Marina et al. 2019). 
TABLE 1. Summary of the masses observed in the nonenzymatic oligomerization reactions of cAMP and cCMP reactions

\begin{tabular}{|c|c|c|c|c|c|c|c|c|}
\hline & Species & $\begin{array}{l}\text { Expected } \\
\text { mass }\end{array}$ & $\begin{array}{l}\text { Observed } \\
\text { mass }\end{array}$ & $\begin{array}{l}\text { Error } \\
(\mathrm{ppm})\end{array}$ & Species & $\begin{array}{l}\text { Expected } \\
\text { mass }\end{array}$ & $\begin{array}{l}\text { Observed } \\
\text { mass }\end{array}$ & $\begin{array}{l}\text { Error } \\
\text { (ppm) }\end{array}$ \\
\hline \multirow{4}{*}{$\begin{array}{l}2^{\prime}-3^{\prime} \\
\text { cNMP }\end{array}$} & cAMP & 330.05 & 330.05 & -0.90 & cCMP & 306.04 & 306.04 & -1.30 \\
\hline & AMP dimer & 677.12 & 677.12 & 2.51 & CMP dimer & 629.10 & 629.10 & -0.15 \\
\hline & AMP trimer & 1006.17 & 1006.17 & 1.78 & CMP trimer & 934.14 & 934.14 & 1.92 \\
\hline & $\begin{array}{l}\text { AMP } \\
\text { tetramer }\end{array}$ & 1335.22 & 1335.23 & 2.62 & $\begin{array}{l}\text { CMP } \\
\text { tetramer }^{a}\end{array}$ & 1239.18 & 1239.18 & 4.59 \\
\hline $3^{\prime}-5^{\prime}$ & cAMP & 330.05 & 330.05 & -1.51 & cCMP & 306.04 & 306.04 & -0.98 \\
\hline cNMP & AMP dimer & 677.12 & 677.12 & 1.77 & CMP dimer & 629.10 & 629.10 & 1.74 \\
\hline
\end{tabular}

aDepicts that the species was observed in TOF-MS but not seen in TOF-MS-MS analysis.

Figure 6 shows the graph of the semi-quantitation done on the HPLC data, which corresponds to the stability of the starting monomer (accounting for both cNMP and NMP). The amount of the starting monomer (either cAMP or cCMP) decreased with increasing $\mathrm{DH}-\mathrm{RH}$ cycles (Fig. 6; Table 2). In the 2', 3' cAMP reactions (without lipid) (Fig. $6 \mathrm{~A})$, cAMP reduces to $80 \%, 50 \%, 30 \%$, and $20 \%$ in four, 10,20 , and 30 cycles, respectively. However, in lipid-assisted reactions, the starting monomer was more stable; up to $60 \%$ of the starting monomer persisted even after $30 \mathrm{DH}-$ $\mathrm{RH}$ cycles. In the case of $3^{\prime}, 5^{\prime}$ cAMP, in both lipid-assisted and lipid-free reactions, only $5 \%$ of the starting monomer underwent breakdown even after $30 \mathrm{DH}-\mathrm{RH}$ cycles. The re- sults suggested that the presence of lipid enhanced the stability of the starting monomer in the $2^{\prime}, 3^{\prime}$ cAMP reaction. However, the protecting effect of lipid was not evident in the reactions with $3^{\prime}, 5^{\prime}$ cAMP as it is inherently much more stable.

In the case of $2^{\prime}, 3^{\prime}$ cCMP reactions (Fig. 6B; Table 2), the quantity of starting monomer reduced by $10 \%, 20 \%$, $40 \%$, and $55 \%$ in four, 10, 20, and $30 \mathrm{~d}$ of DH-RH cycling, respectively, in both the without lipid and lipid-assisted reactions. $3^{\prime}, 5^{\prime}$ cCMP was found to be more stable than the $2^{\prime}, 3^{\prime}$ cCMP under our reaction conditions, similar to what was observed with cAMP isomers. In all, the concentration of $3^{\prime}, 5^{\prime}$ cCMP reduced to $95 \%$ of its initial concentration in
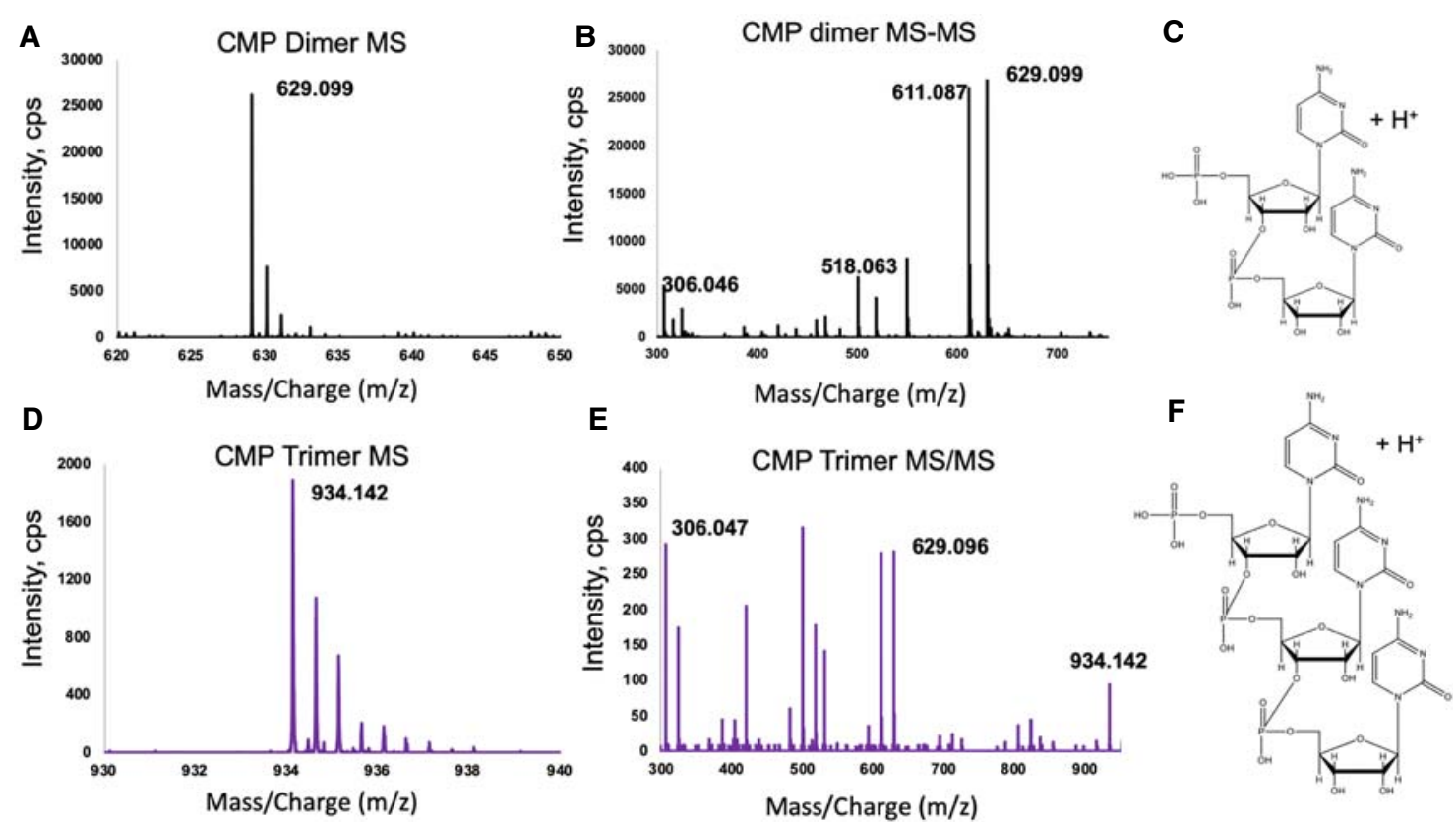

FIGURE 5. Representative spectra of TOF-MS and TOF-MS/MS in ESI positive mode for cCMP reactions. The figure represents the TOF-MS spectrum, TOF-MS/MS spectrum, and the structures that were observed for the $\mathrm{H}^{+}$adducts of CMP linear dimer (A-C) with monoisotopic mass 629.1 $\mathrm{Da}$, and CMP linear trimer $(D-F)$ with monoisotopic mass $934.14 \mathrm{Da}$, respectively. 


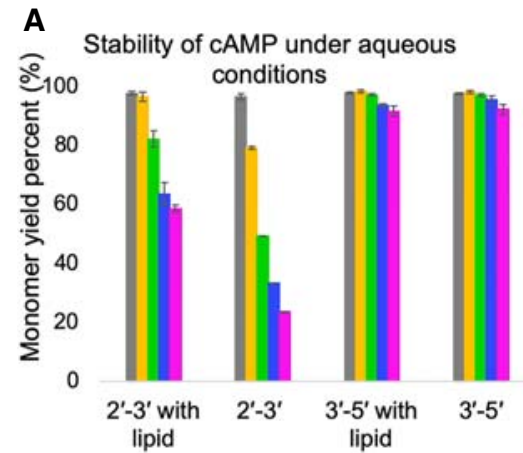

FIGURE 6. The stability of cyclic nucleotides in enzyme-free oligomerization reactions, in both, without lipid and lipid-assisted reactions. The graphs show the stability of the cAMP $(A)$ and $c C M P(B)$, during the reactions carried out under $\mathrm{DH}-\mathrm{RH}$ regimen, either in the presence or absence of lipids. $X$-axis shows different reactions with indicated cNMP. Different colors depict different $\mathrm{DH}-\mathrm{RH}$ cycles. Y-axis shows corresponding cNMP percent remaining, normalized to that present in cycle zero. Error bars indicate SD.

$30 \mathrm{DH}-\mathrm{RH}$ cycles. Hence the lipid did not seem to have any influence on the cCMP reactions, both, in the case of $2^{\prime}-3^{\prime}$ cCMP and $3^{\prime}-5^{\prime}$ cCMP reactions. As alluded to earlier, the protecting effect of lipid on a particular solute molecule could stem from either its entrapment inside a vesicle/within bilayers, or by directly interacting with the amphiphilic surfaces. However, the mechanisms of interaction can vary for different molecules and might depend on the variables such as planarity, hydrophobicity, and hydrogen bonding (Black et al. 2013). Purines are shown to bind fatty acid membranes more than pyrimidines, mainly via hydrophobic interactions (Black et al. 2013). The reduced binding of pyrimidine nucleobases/nucleotides with lipid could possibly explain the negligible effect of the lipid in the case of nonenzymatic oligomerization reactions involving cCMP.

\section{Nonenzymatic oligomerization reactions of cyclic nucleotides in hot spring water}

To obtain a more realistic picture of the oligomerization phenomenon involving cyclic nucleotides, the enzyme-free oligomerization reactions were also performed using water samples collected from a hot spring. Few previous studies have demonstrated that the presence of certain metal ions can catalyze nonenzymatic oligomerization reactions of nucleotides (Lailach et al. 1968; Ferris 2005; Joshi et al. 2012). Thus, metal ions present in a hot spring could also potentially affect nonenzymatic oligomerization. Nonetheless, high amounts of salt are also known to be detrimental for RNA (Blasko and Bruice 1999). Panamic hot spring water that was used in the study by Joshi et al. (2017) was chosen to investigate the aforementioned oligomerization reactions in detail. This site was studied as part of the Spaceward Bound expedition to Ladakh, an astrobiologically relevant site in the northern part of India (Pandey et al. 2020). It is considered as an early Earth and a Martian equivalent site due to its various topological features. Panamic water sample has a total salt content of around 7.6-7.9 mM, with predominantly $\mathrm{Na}^{+}$as major cation ( 92.5\%) followed by $\mathrm{Ca}^{2+}(\sim 5 \%), \mathrm{K}^{+}(\sim 2 \%), \mathrm{Li}^{+}$ ( 0.7\%), and $\mathrm{Mg}^{2+}(\sim 0.03 \%)$ ions. $\mathrm{HCO}_{3}^{-}$was found to be the major anion ( 82\%) followed by $\mathrm{SO}_{4}^{2-}(\sim 14.3 \%)$ and $\mathrm{Cl}^{-}$( 3.8\%) (Table 3). The reaction conditions such as temperature and other parameters like reactants

TABLE 2. Stability of cyclic nucleotides in enzyme-free oligomerization reactions, in both, without lipid and lipid-assisted reactions

\begin{tabular}{|c|c|c|c|c|c|}
\hline & \multicolumn{5}{|c|}{ cAMP } \\
\hline & Cycle 0 & Cycle 4 & Cycle 10 & Cycle 20 & Cycle 30 \\
\hline $2^{\prime}-3^{\prime}$ with lipid & $97.76 \pm 0.62$ & $96.55 \pm 1.59$ & $82.29 \pm 2.66$ & $63.66 \pm 3.71$ & $58.60 \pm 1.14$ \\
\hline $2^{\prime}-3^{\prime}$ & $96.59 \pm 1.12$ & $79.24 \pm 0.61$ & $49.32 \pm 0.14$ & $33.24 \pm 0.13$ & $23.61 \pm 0.10$ \\
\hline $3^{\prime}-5^{\prime}$ with lipid & $98 \pm 0.22$ & $98.44 \pm 0.51$ & $97.26 \pm 0.52$ & $93.71 \pm 0.44$ & $91.70 \pm 1.64$ \\
\hline \multirow[t]{3}{*}{$3^{\prime}-5^{\prime}$} & $97.66 \pm 0.24$ & $98.11 \pm 0.47$ & $97.16 \pm 0.49$ & $95.58 \pm 1.34$ & $92.31 \pm 1.73$ \\
\hline & \multicolumn{5}{|c|}{ cCMP } \\
\hline & Cycle 0 & Cycle 4 & Cycle 10 & Cycle 20 & Cycle 30 \\
\hline $2^{\prime}-3^{\prime}$ with lipid & $98.25 \pm 0.00$ & $91.57 \pm 0.24$ & $83.61 \pm 1.00$ & $58.95 \pm 0.46$ & $45.09 \pm 1.58$ \\
\hline $2^{\prime}-3^{\prime}$ & $98.29 \pm 0.00$ & $92.89 \pm 0.94$ & $87.31 \pm 1.24$ & $64.51 \pm 3.00$ & $48.70 \pm 2.21$ \\
\hline $3^{\prime}-5^{\prime}$ with lipid & $99.88 \pm 0.02$ & $97.69 \pm 2.18$ & $96.50 \pm 0.12$ & $94.24 \pm 0.36$ & $94.57 \pm 0.47$ \\
\hline $3^{\prime}-5^{\prime}$ & $99.95 \pm 0.01$ & $96.24 \pm 0.02$ & $96.85 \pm 0.06$ & $96.13 \pm 1.00$ & $95.51 \pm 0.21$ \\
\hline
\end{tabular}


TABLE 3. Geochemical analysis of Panamic hot spring water sample

\begin{tabular}{|c|c|c|c|c|c|c|c|c|c|c|c|}
\hline \multirow[b]{2}{*}{ Hot spring water } & \multicolumn{5}{|c|}{ Major cations } & \multicolumn{3}{|c|}{ Major anions } & \multirow[b]{2}{*}{$\mathrm{TZ}^{+}$} & \multirow[b]{2}{*}{$\mathrm{TZ}^{-}$} & \multirow[b]{2}{*}{$\mathrm{TZ}^{+} / \mathrm{TZ}$} \\
\hline & $\mathrm{Na}^{+}$ & $\mathrm{K}^{+}$ & $\mathrm{Ca}^{2+}$ & $\mathrm{Mg}^{2+}$ & $\mathrm{Li}^{+}$ & $\mathrm{HCO}_{3}^{-}$ & $\mathrm{Cl}^{-}$ & $\mathrm{SO}_{4}^{2-}$ & & & \\
\hline & \multicolumn{7}{|c|}{ All values in $\mathrm{mM}$} & \multicolumn{4}{|c|}{$\mu \mathrm{E}$} \\
\hline Panamic & 6.76 & 0.14 & 0.36 & 0.002 & 0.05 & 5.68 & 0.26 & 0.99 & 7665 & 7918 & 0.97 \\
\hline
\end{tabular}

concentrations were kept identical to what was described for the aforesaid reactions that were studied in nanopure water (i.e., $30 \mathrm{DH}-\mathrm{RH}$ cycles, each cycle consists of $24 \mathrm{~h}$ at $90^{\circ} \mathrm{C}$ ). The native $\mathrm{pH}$ of the hot spring water sample was $~ 8-8.5$, which was kept as is in the experiments undertaken.

Figure 8 gives a comparative abundance of the different oligomeric species (normalized to CNMP at cycle 0) that were observed in CAMP and CCMP both in the presence and absence of lipid (POPC), in nanopure and hot spring water reactions (Fig. 8; Table 4). All the oligomers were characterized using LC-MS and MS/MS analysis. Lipidfree reactions of $2^{\prime}, 3^{\prime}$ cAMP yielded oligomers up to intact AMP linear tetramer after four DH-RH cycles. However, it seemed to degrade after 10 cycles of DH-RH. AMP linear trimer was also observed to disappear after $20 \mathrm{DH}-\mathrm{RH}$ cycles. On the contrary, in lipid-assisted reactions, 2', 3' cAMP oligomerized to yield linear trimer in $4 \mathrm{~d}$ of $\mathrm{DH}-$ $\mathrm{RH}$ cycling and persisted even after $30 \mathrm{DH}-\mathrm{RH}$ cycles, indicating the stabilizing effect of lipid. However, in the case of $3^{\prime}, 5^{\prime}$ cAMP reaction, only a dimer was observed after 10 $\mathrm{DH}-\mathrm{RH}$ cycles, both, in the presence and absence of lipid. Therefore, the presence of lipid did not seem to make any significant difference in this case. In $2^{\prime}, 3^{\prime}$ cCMP lipid-assisted and the without lipid reactions, CMP linear trimer was observed after $10 \mathrm{DH}-\mathrm{RH}$ cycles, which was stable throughout the reaction, that is, till 30 cycles. The experiments with $3^{\prime}, 5^{\prime}$ cCMP yielded linear dimer after $20 \mathrm{DH}-$ $\mathrm{RH}$ cycles. In general, the metal ions and other co-solutes (like bicarbonates, etc.) present in the hot spring water sample seemed to increase the rate of oligomerization reaction, albeit destabilizing the resultant oligomers too.

\section{Stability of POPC vesicles under multiple DH-RH cycles in nanopure vs Panamic water}

Our results demonstrated that the presence of POPC could indeed enhance the stability of the starting monomer and oligomers in some of the reactions that were investigated $\left(2^{\prime}, 3^{\prime}\right.$ cAMP in both nanopure and Panamic water) under $\mathrm{DH}-\mathrm{RH}$ conditions. This corroborates with previous studies that have reported a similar protective effect coming from the presence of lipids in the reaction milieu (Rajamani et al. 2008; Mungi et al. 2015). As dis- cussed by Damer and Deamer (2015), lipid bilayers can do so by trapping the substrate molecules in the interlamellar spaces during the dry phase. Coincidentally, this also provides a concentration effect thereby facilitating uphill forward reactions like oligomerization. Furthermore, the lipids would also encapsulate the resultant oligomers upon rehydration, thus protecting them from back reactions like hydrolysis, which leads to their accumulation over multiple cycles. However, to the best of our knowledge, none of the previous studies have examined the stability of the POPC vesicles under multiple $\mathrm{DH}-\mathrm{RH}$ cycles for a prolonged duration, for example, for $30 \mathrm{~d}$, as was done in this study. In order to evaluate whether the lipid vesicles are stable under our reaction conditions, 1 $\mathrm{mM}$ of POPC was used and DH-RH cycling was performed, both, in nanopure water and Panamic water samples at $\mathrm{pH} 8$ for $30 \mathrm{~d}$. The stability of the POPC vesicles was monitored by observing them under a microscope after a different number of DH-RH cycles using differential interference contrast (DIC) microscopy (Methods). Vesicles were observed in nanopure water reactions even after $30 \mathrm{DH}-\mathrm{RH}$ cycles (Fig. 7A). On the contrary, small aggregates (collapsed vesicles) were observed along with vesicles after 20 and $30 \mathrm{DH}-\mathrm{RH}$ cycles in the Panamic water sample (Fig. 7B). Nonetheless, an important aspect to consider here is that the mere presence of vesicles does not necessarily have to be a direct reflection of the molecular stability of POPC. Previous literature in the field has demonstrated that the fatty acid chains can also self-assemble into vesicles around the $\mathrm{pH}$ that is near or equal to their pKa (Monnard and Walde 2015). Oleic acid has a pKa around 8.5. Consequently, at our reaction $\mathrm{pH}$, that is, 8 , if POPC is degrading to its components, the resulting oleic acid can potentially form vesicles. Thus, the vesicles observed could also be a false positive indication for the stability of POPC. Therefore, the chemical stability of POPC molecules was also evaluated using thin layer chromatography (TLC) (Methods). POPC seemed to be comparatively more stable (stable up to $30 \mathrm{DH}-\mathrm{RH}$ cycles) in nanopure water (Fig. 7C) than in the Panamic water reaction. TLC band corresponding to POPC (band indicated by black solid arrow) disappeared by $30 \mathrm{DH}-\mathrm{RH}$ cycles in the Panamic water sample reaction (Fig. 7D). With increasing $\mathrm{DH}-\mathrm{RH}$ cycles, there were also some new bands that 
TABLE 4. Nonenzymatic oligomerization of cyclic nucleotides as observed using LC-MS analysis

\begin{tabular}{|c|c|c|c|c|c|c|c|c|c|}
\hline & \multirow[b]{3}{*}{ Cycles } & \multicolumn{8}{|c|}{ cAMP } \\
\hline & & \multicolumn{4}{|c|}{ Nanopure water } & \multicolumn{4}{|c|}{ Panamic water } \\
\hline & & cNMP & Dimer & Trimer & Tetramer & cNMP & Dimer & Trimer & Tetramer \\
\hline $2^{\prime}-3^{\prime}$ cAMP with lipid & $\begin{array}{r}0 \\
4 \\
10 \\
20 \\
30\end{array}$ & $\begin{array}{l}1 \times 10^{07} \\
1 \times 10^{07} \\
5 \times 10^{06} \\
3 \times 10^{06} \\
2 \times 10^{06}\end{array}$ & $\begin{array}{l}1 \times 10^{05} \\
1 \times 10^{06} \\
8 \times 10^{05} \\
8 \times 10^{05}\end{array}$ & $\begin{array}{l}6 \times 10^{03} \\
1 \times 10^{05} \\
8 \times 10^{04} \\
8 \times 10^{04}\end{array}$ & $\begin{array}{l}5 \times 10^{04} \\
2 \times 10^{04} \\
2 \times 10^{04}\end{array}$ & $\begin{array}{l}6 \times 10^{06} \\
8 \times 10^{06} \\
2 \times 10^{06} \\
1 \times 10^{06} \\
2 \times 10^{06}\end{array}$ & $\begin{array}{l}1 \times 10^{06} \\
1 \times 10^{06} \\
8 \times 10^{05} \\
6 \times 10^{05}\end{array}$ & $\begin{array}{l}2 \times 10^{05} \\
8 \times 10^{04} \\
8 \times 10^{04} \\
6 \times 10^{04}\end{array}$ & \\
\hline $2^{\prime}-3^{\prime}$ cAMP & $\begin{array}{r}0 \\
4 \\
10 \\
20 \\
30\end{array}$ & $\begin{array}{l}6 \times 10^{06} \\
1 \times 10^{07} \\
1 \times 10^{07} \\
1 \times 10^{07} \\
4 \times 10^{06}\end{array}$ & $\begin{array}{l}1 \times 10^{05} \\
6 \times 10^{05} \\
5 \times 10^{05} \\
6 \times 10^{05}\end{array}$ & $\begin{array}{l}5 \times 10^{04} \\
7 \times 10^{04} \\
7 \times 10^{04}\end{array}$ & $\begin{array}{l}5 \times 10^{04} \\
6 \times 10^{04}\end{array}$ & $\begin{array}{l}1 \times 10^{07} \\
1 \times 10^{07} \\
6 \times 10^{05} \\
6 \times 10^{05} \\
5 \times 10^{05}\end{array}$ & $\begin{array}{l}9 \times 10^{05} \\
9 \times 10^{05} \\
5 \times 10^{05} \\
6 \times 10^{05}\end{array}$ & $\begin{array}{l}9 \times 10^{04} \\
4 \times 10^{04}\end{array}$ & $7 \times 10^{04}$ \\
\hline $3^{\prime}-5^{\prime}$ cAMP with lipid & $\begin{array}{r}0 \\
4 \\
10 \\
20 \\
30\end{array}$ & $\begin{array}{l}1 \times 10^{07} \\
9 \times 10^{06} \\
1 \times 10^{07} \\
1 \times 10^{07} \\
9 \times 10^{06}\end{array}$ & $\begin{array}{l}3 \times 10^{04} \\
3 \times 10^{04}\end{array}$ & & & $\begin{array}{l}2 \times 10^{07} \\
1 \times 10^{07} \\
1 \times 10^{07} \\
1 \times 10^{07} \\
1 \times 10^{07}\end{array}$ & $\begin{array}{l}2 \times 10^{04} \\
2 \times 10^{04} \\
3 \times 10^{04}\end{array}$ & & \\
\hline \multirow[t]{3}{*}{$3^{\prime}-5^{\prime}$ сAMP } & $\begin{array}{r}0 \\
4 \\
10 \\
20 \\
30\end{array}$ & $\begin{array}{l}1 \times 10^{07} \\
8 \times 10^{06} \\
8 \times 10^{06} \\
1 \times 10^{07} \\
7 \times 10^{06}\end{array}$ & $\begin{array}{l}2 \times 10^{04} \\
4 \times 10^{03}\end{array}$ & & & $\begin{array}{r}2 \times 10^{07} \\
1 \times 10^{07} \\
2 \times 10^{07} \\
1 \times 10^{07} \\
2 \times 10^{07}\end{array}$ & $\begin{array}{l}5 \times 10^{03} \\
3 \times 10^{03} \\
9 \times 10^{03}\end{array}$ & & \\
\hline & & \multicolumn{4}{|c|}{ Nanopure water } & \multicolumn{4}{|c|}{ Panamic water } \\
\hline & Cycles & cNMP & Dimer & Trimer & Tetramer & cNMP & Dimer & Trimer & Tetramer \\
\hline $2^{\prime}-3^{\prime}$ cCMP with lipid & $\begin{array}{r}0 \\
4 \\
10 \\
20 \\
30\end{array}$ & $\begin{array}{l}9 \times 10^{06} \\
1 \times 10^{07} \\
1 \times 10^{04} \\
4 \times 10^{06} \\
7 \times 10^{04}\end{array}$ & $\begin{array}{l}5 \times 10^{05} \\
7 \times 10^{05} \\
5 \times 10^{05}\end{array}$ & $\begin{array}{l}2 \times 10^{04} \\
1 \times 10^{04} \\
5 \times 10^{03}\end{array}$ & & $\begin{array}{l}8 \times 10^{06} \\
5 \times 10^{06} \\
4 \times 10^{06} \\
2 \times 10^{06} \\
2 \times 10^{06}\end{array}$ & $\begin{array}{l}2 \times 10^{06} \\
1 \times 10^{06} \\
1 \times 10^{06} \\
8 \times 10^{05}\end{array}$ & $\begin{array}{l}1 \times 10^{05} \\
6 \times 10^{04} \\
4 \times 10^{04} \\
2 \times 10^{04}\end{array}$ & \\
\hline $2^{\prime}-3^{\prime}$ сCMP & $\begin{array}{r}0 \\
4 \\
10 \\
20 \\
30\end{array}$ & $\begin{array}{l}7 \times 10^{06} \\
8 \times 10^{06} \\
8 \times 10^{06} \\
5 \times 10^{06} \\
4 \times 10^{06}\end{array}$ & $\begin{array}{l}1 \times 10^{05} \\
4 \times 10^{05} \\
7 \times 10^{05} \\
7 \times 10^{05}\end{array}$ & $\begin{array}{l}4 \times 10^{03} \\
1 \times 10^{04} \\
1 \times 10^{04} \\
1 \times 10^{04}\end{array}$ & & $\begin{array}{l}6 \times 10^{06} \\
6 \times 10^{06} \\
4 \times 10^{06} \\
3 \times 10^{06} \\
3 \times 10^{06}\end{array}$ & $\begin{array}{l}1 \times 10^{06} \\
1 \times 10^{06} \\
1 \times 10^{06} \\
1 \times 10^{06}\end{array}$ & $\begin{array}{l}7 \times 10^{04} \\
6 \times 10^{04} \\
4 \times 10^{04} \\
3 \times 10^{04}\end{array}$ & \\
\hline $3^{\prime}-5^{\prime}$ cCMP with lipid & $\begin{array}{r}0 \\
4 \\
10 \\
20 \\
30\end{array}$ & $\begin{array}{l}2 \times 10^{04} \\
2 \times 10^{05} \\
1 \times 10^{05} \\
2 \times 10^{05} \\
4 \times 10^{05}\end{array}$ & $\begin{array}{l}2 \times 10^{04} \\
1 \times 10^{04} \\
2 \times 10^{04}\end{array}$ & & & $\begin{array}{l}4 \times 10^{04} \\
2 \times 10^{05} \\
3 \times 10^{05} \\
4 \times 10^{05} \\
4 \times 10^{05}\end{array}$ & $\begin{array}{l}6 \times 10^{04} \\
1 \times 10^{05} \\
2 \times 10^{05} \\
2 \times 10^{05}\end{array}$ & & \\
\hline $3^{\prime}-5^{\prime}$ cсMP & $\begin{array}{r}0 \\
4 \\
10 \\
20 \\
30\end{array}$ & $\begin{array}{l}4 \times 10^{04} \\
1 \times 10^{05} \\
1 \times 10^{05} \\
1 \times 10^{05} \\
4 \times 10^{05}\end{array}$ & $\begin{array}{l}3 \times 10^{04} \\
2 \times 10^{04} \\
1 \times 10^{04} \\
3 \times 10^{04}\end{array}$ & & & $\begin{array}{l}6 \times 10^{04} \\
3 \times 10^{05} \\
2 \times 10^{05} \\
2 \times 10^{05} \\
3 \times 10^{05}\end{array}$ & $\begin{array}{l}3 \times 10^{04} \\
7 \times 10^{04} \\
8 \times 10^{04} \\
1 \times 10^{05}\end{array}$ & & \\
\hline
\end{tabular}

The abundance of linear oligomeric species observed in the nonenzymatic oligomerization reactions of cAMP and cCMP in both nanopure water and Panamic water. All the reactions were analyzed using TOF-MS and confirmed with TOF-MS-MS analysis.

were observed, which correspond to the degradation products. These were mainly fatty acids (palmitic acid and oleic acid) and monoacylated phospholipid, whose identity was confirmed by high-resolution mass-spectrom- etry (HRMS). As mentioned earlier, fatty acids (oleic acid) on their own have a tendency to form vesicles at $\mathrm{pH}$ 8. So, the vesicles observed in the Panamic water sample after 30 cycles of DH-RH using microscopy (Fig. 7B) could 


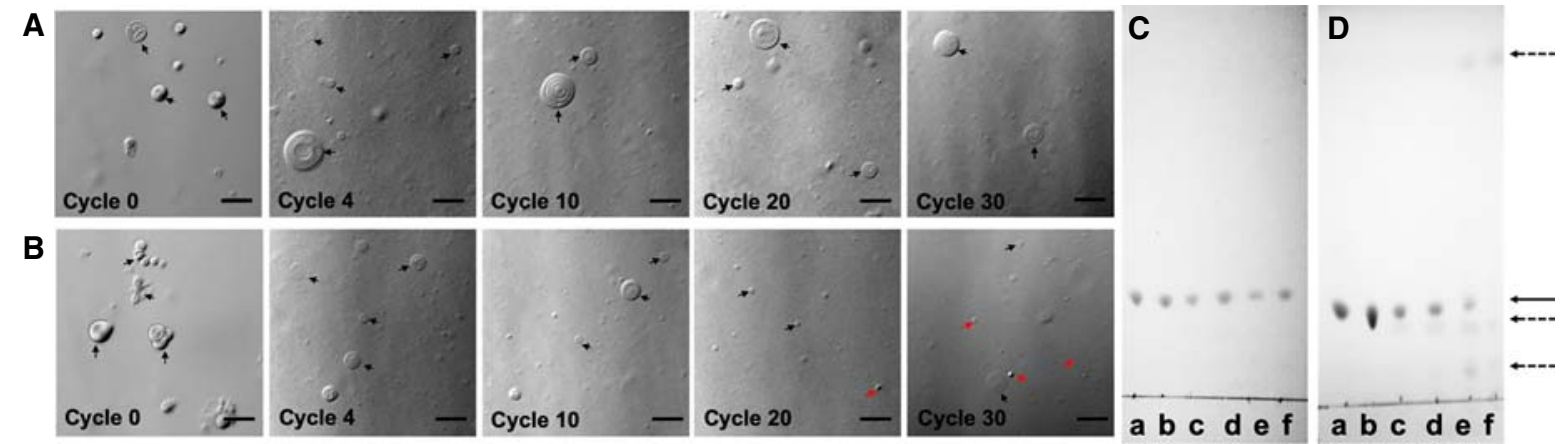

FIGURE 7. The stability of POPC vesicles under our reaction conditions. The stability of POPC vesicles under oligomerization reaction conditions with increasing $\mathrm{DH}-\mathrm{RH}$ cycles (left to right), viz. cycle 0 , cycle 4, cycle 10, cycle 20, cycle 30, either in nanopure water $(A)$ or in Panamic water sample (B). The black and red arrows indicate vesicles and aggregates (collapsed vesicles), respectively. The scale bar in all the images is 10 $\mu \mathrm{m}$. The chemical stability of POPC molecules under DH-RH conditions in nanopure water $(C)$ and Panamic water $(D)$. Different lanes from left to right, that is, a to f, indicate POPC control, the reactions corresponding to DH-RH cycle 0, cycle 4, cycle 10, cycle 20, and cycle 30, respectively. Solid black arrow indicates the band corresponding to POPC, dashed black arrows indicate new bands that appear corresponding to degradation products.

also be pure fatty acid vesicles or a blended membrane composed of POPC and fatty acid. This is interesting as POPC, being a diacyl structure, can provide stability toward fluctuating $\mathrm{pH}$ conditions and the presence of metal ions, while the presence of fatty acid can allow the membrane to exchange material with the bulk solution (Luisi et al. 1999; Mansy 2009; Budin and Szostak 2011; Dalai et al. 2018; Jin et al. 2018; Sarkar et al. 2020). These are properties that have been argued to be highly desirable in model protocellular membranes.

\section{DISCUSSION}

Cyclic nucleotides have been hypothesized to undergo oligomerization via base-catalyzed reaction (Costanzo et al. 2012). Nonenzymatic oligomerization of purine cyclic nucleotides has been demonstrated under complete dry conditions (Verlander et al. 1973; Costanzo et al. 2012, 2016). However, to our knowledge, only a few studies have tried to investigate the nonenzymatic oligomerization of cyclic pyrimidine nucleotides (Tapiero and Nagyvary 1971; Costanzo et al. 2017). The present study illustrates the enzyme-free oligomerization resulting in the formation of intact informational oligomers in both a purine (cAMP) and a pyrimidine (cCMP) system, under prebiotically relevant $\mathrm{DH}-\mathrm{RH}$ conditions as well as in a hot spring water sample reminiscent of candidate early Earth environments. It has been reported that short oligomers (up to trimers) can enhance the rate of template-directed replication by about threefold (Kaiser and Richert 2013; Li et al. 2017; Tam et al. 2017; O'Flaherty et al. 2018). Thus, the intact oligomers reported in the present study can potentially assist in the information propagation in template-directed replication scenarios.
Our study demonstrates that prebiotically relevant $\mathrm{DH}_{-}$ $\mathrm{RH}$ cycles can indeed facilitate the enzyme-free oligomerization of, both, 2', 3' and $3^{\prime}, 5^{\prime}$ isomers of cyclic nucleotides of both purine and pyrimidine systems. The dry phase facilitates the condensation reaction, although, the rehydration phase is necessary for effective collisions to

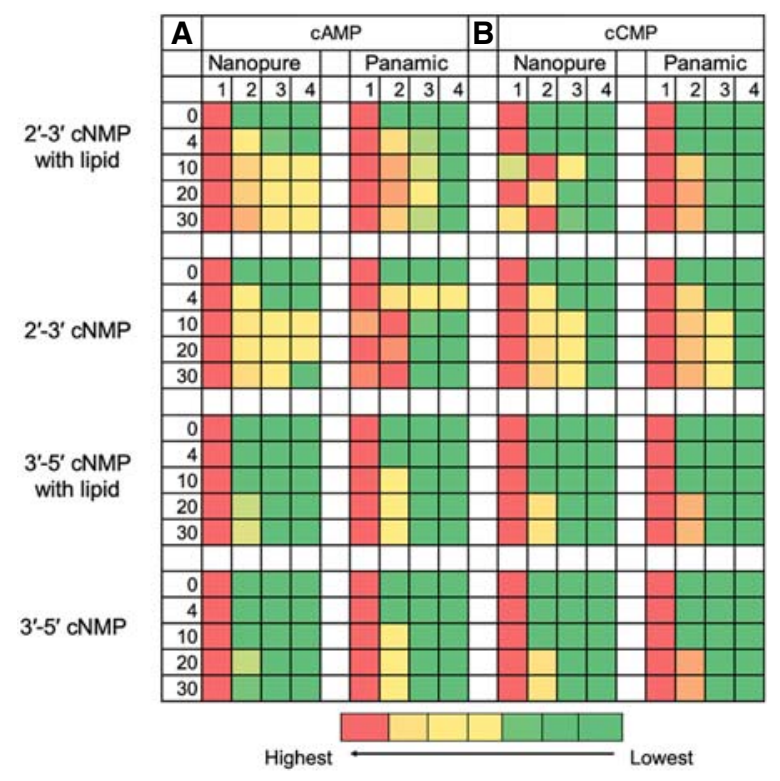

FIGURE 8. Heat map of all the species observed in enzyme-free oligomerization reactions using LC-MS/MS. $(A, B)$ The species observed in different reactions of CAMP, and CCMP, respectively, as mentioned toward the left of the figure. The numbers, viz. 0, 4, 10, 20, and 30, on the left axis of the heat map indicate the number of $\mathrm{DH}-\mathrm{RH}$ cycles. Lanes 1-4 show the presence of CNMP, dimer, trimer, and tetramer, respectively. Each block depicts a single reaction with rows and columns, signifying different time points and different species observed, respectively. The numerical data used for this analysis are presented in Table 4. 
occur between monomers and/or the growing oligomers. The latter, however, can also enhance the back hydrolysis of oligomers that are already present. Therefore, there is always a dynamical interplay of oligomerization and hydrolysis in these geological settings. Subsequent cycles of $\mathrm{DH}-\mathrm{RH}$ can act as a kinetic trap by pushing the reaction toward oligomerization, thereby facilitating the formation of longer oligomers over multiple cycles (Rajamani et al. 2008; Mungi et al. 2015). In these settings, lipids can provide a boundary condition and facilitate the formation of a protocellular entity by encapsulating and thus, conferring protection to select solute molecules (as seen in the case of 2', 3' cAMP reactions in both the water samples) (Damer and Deamer 2015). In addition to the formation of intact linear oligomers, the formation of oligomers with cyclic ends (cyclic oligomers) could also potentially be facilitated in the reactions studied. When present in reasonable concentrations, these cyclic oligomers could possibly undergo ligation-like reactions resulting in longer oligomers. Nonetheless, the structure of these cyclic oligomers cannot be unequivocally ascertained using LC-MS as the mass of the covalently linked cyclic oligomer and noncovalently linked stacked oligomers happen to be the same. This is an aspect that has also been highlighted in other studies too (e.g., Kaddour et al. 2018).

In the hot spring water sample reactions, the oligomers seemed to form more readily, as was observed, for example, in the reactions involving 2', 3' cAMP (tetramer was observed after $4 \mathrm{~d}$ of DH-RH cycles) (Fig. 8A). However, the oligomers formed were also found to be susceptible to hydrolysis, potentially because of the presence of different metal ions or other co-solutes in these scenarios. Interestingly, 2', 3' cNMP, upon oligomerization could potentially yield $2^{\prime}, 5^{\prime}$ as well as $3^{\prime}, 5^{\prime}$ linked phosphodiester bonds (Fig. 2; Costanzo et al. 2016). On the contrary, 3', 5' cNMP can oligomerize to yield only 3', 5' linked phosphodiester bonds. Given this, it is logical to assume that the enzyme-free oligomerization of both the cyclic nucleotide isomers $\left(2^{\prime}, 3^{\prime}\right.$ and $\left.3^{\prime}, 5^{\prime}\right)$ might result in products with mixed phosphodiester linkages. Significantly, 2', 5' phosphodiester linkages are more prone to hydrolysis even at $\mathrm{pH} 8$ and $40^{\circ} \mathrm{C}$ with a rate of hydrolysis of about $0.01 / \mathrm{h}$ as compared to $0.003 / \mathrm{h}$ for $3^{\prime}, 5^{\prime}$ linkages (Usher and McHale 1976), indicating that this could only get even more exaggerated at $90^{\circ} \mathrm{C}$ (that we used in our experiments). Our study emphasizes the fact that even though the speed of oligomerization of $3^{\prime}, 5^{\prime}$ cNMPs is compromised, the resultant oligomers are found to be stable even after $30 \mathrm{DH}-\mathrm{RH}$ cycles (Fig. 8). The comparatively less stable products resulting in $2^{\prime}, 3^{\prime}$ cNMP oligomerization (especially in cAMP reactions in Panamic water) could be due to the formation of more hydrolyzable 2', 5' linked oligomers, in comparison to the $3^{\prime}, 5^{\prime}$ linked oligomers. The results from our reactions pertaining to the hot spring water sample (a proxy for prebiotically pertinent condi- tions), could, therefore, be indicative for how the selection of $3^{\prime}, 5^{\prime}$ phosphodiester linkages might have been driven by such relevant selection pressures. We propose that in candidate prebiotic environments (e.g., hot spring waters) or in the presence of metal ions, selection for the $3^{\prime}, 5^{\prime}$ phosphodiester linkage over time might have been naturally facilitated. Additionally, our results seemed to indicate that the presence of ions and other co-solutes (such as silicates) in the hot spring water sample, could effectively act as a selection pressure playing an important role in shaping the evolutionary landscape of a putative RNA World. Altogether, this study provides a comprehensive and robust means by which enzyme-free oligomerization of intrinsically activated, prebiotically pertinent nucleotides might have occurred in a heterogenous prebiotic soup.

\section{MATERIALS AND METHODS}

\section{Materials}

The monosodium salts of all four cyclic monophosphates viz. adenosine $3^{\prime}, 5^{\prime}$-cyclic monophosphate ( $3^{\prime}, 5^{\prime}$-cAMP), adenosine $2^{\prime}, 3^{\prime}$-cyclic monophosphate (2', 3'-cAMP), cytosine 3', 5'-cyclic monophosphate $\left(3^{\prime}, 5^{\prime}\right.$-cCMP), cytosine $2^{\prime}, 3^{\prime}$-cyclic monophosphate $\left(2^{\prime}, 3^{\prime}-\mathrm{cCMP}\right)$, adenosine monophosphate (AMP) linear dimer, trimer, and tetramer were purchased from Sigma-Aldrich and used without further purification. 1-palmitoyl-2-oleoyl-snglycero-3-phosphocholine (POPC) was purchased from Avanti Polar Lipids Inc. All other reagents used were of analytical grade and purchased from Sigma-Aldrich. TLC Silica gel $60 F_{254}$ was purchased from Merck (EMD Millipore Corporation).

\section{Methods}

\section{Simulating early-Earth-like conditions}

Early Earth-like conditions were simulated using a bench-top heating block that was maintained at high temperatures, that is, $90^{\circ} \mathrm{C}$ as described by Mungi et al. (2015). The oligomerization reactions were carried out in $20 \mathrm{~mL}$ glass vials with their caps fitted with PTFE septa purchased from Chemglass. The anaerobic environment was maintained by delivering a gentle flow of carbon dioxide into the vials through two PEEK tubings of about 1-1.5 in, one acting as an inlet and another as an outlet for the gas.

\section{Vesicle solution preparation}

The vesicle solutions were prepared by drying the required amount of chloroform solution (with strength $25 \mathrm{mg} / \mathrm{mL}$ ) of POPC under nitrogen gas flow to prepare a dry lipid film. It was then kept under vacuum for 5-6 $\mathrm{h}$ to make sure that no trace amount of chloroform remained. Subsequently, nanopure water was used to rehydrate the thin film to form the vesicles. 


\section{Nonenzymatic oligomerization reaction conditions and procedure}

A typical reaction mixture consisted of $5 \mathrm{mM}$ cyclic nucleotide in nanopure water with $\mathrm{pH} \sim 8.5$ or hot spring water sample. In lipidassisted reactions $1 \mathrm{mM}$ of POPC was added to each reaction to maintain a constant ratio of 5:1 for nucleotide to lipid. The lipid concentration was chosen based on a previous study in our laboratory (Mungi et al. 2015). The samples were rehydrated with nanopure water, and mixed properly followed by a prolonged dehydration phase during each $\mathrm{DH}-\mathrm{RH}$ cycle, with $24 \mathrm{~h}$ per cycle. The rehydrated samples were collected at different periods. The lipid was extracted from the rehydrated sample using a prestandardized butanol-hexane extraction procedure. The aqueous portion containing nucleotides was collected, and analyzed using HPLC and LC-MS/MS.

\section{Microscopic analysis}

Ten microliters of the reaction sample containing only $1 \mathrm{mM}$ of POPC, was placed on a glass slide which was then evenly spread and covered with a $18 \times 18 \mathrm{~mm}$ coverslip. This was then air sealed by covering its four sides with liquid paraffin. This was done in order to decrease the motion of solution. The slides prepared were then observed under $40 \times$ magnification using a DIC microscope Axiolmager $\mathrm{Z1}$, $(\mathrm{NA}=0.75)$ to check for the presence of lipid vesicles.

\section{HPLC analysis}

HPLC analysis was performed using Infinity series 1260 HPLC instrument (Agilent Technologies). The reaction products, after removing the lipid molecules using previously standardized butanol-hexane extraction (Mungi et al. 2015), were loaded onto HPLC. The molecules were separated by an anion-exchange column viz. DNAPac PA 200 (Thermo Scientific). It separates the molecules based on their interaction with the column through phosphate moiety, thus providing single-nucleotide resolution. The separation method was standardized using a gradient of sodium perchlorate as an eluting solvent and commercially available cAMP monomer, linear AMP monomer, dimer, trimer, and tetramer as standards. A photo diode-array detector (DAD) was used to detect analytes at $260 \mathrm{~nm}$, using a highly sensitive 60 $\mathrm{mm}$ flow cell. The separation between a dead volume peak (which was later characterized as open ring structures lacking phosphate moiety, i.e., adenosine or adenine by mass), cAMP monomer, linear AMP monomer, and oligomers was observed in a typical HPLC chromatogram. The analytes were semi-quantified by measuring the area under corresponding peaks separated through the column. Although the semi-quantified area can be due to the presence of various species with the same charge, it can still provide us with the distribution of species in the reaction after a particular DH-RH cycle.

\section{Mass analysis}

Mass analysis of the samples was performed on a Sciex X500R QTOF mass spectrometer (MS) fitted with an Exion-LC series UHPLC (Sciex) using information-dependent acquisition (IDA) scanning method. The acquired data were analyzed using the Sciex OS software (Sciex; University of Florida). The crude reac- tion mixture was separated on Zorbax C8 column (dimensions: $4.6 \times 150 \mathrm{~mm}, 3.6 \mu \mathrm{m}$ particle size) (Thermo Scientific) fitted with its guard column. A gradient of nanopure water containing $0.1 \%$ formic acid and acetonitrile containing $0.1 \%$ formic acid was used to separate the oligomers. All the mass acquisition was performed using electron spray ionization (ESI) with the following parameters: turbo spray ion source, medium collision gas, curtain gas $=30 \mathrm{~L} / \mathrm{min}$, ion spray voltage $=5500 \mathrm{~V}$ (positive mode), at $500^{\circ} \mathrm{C}$. TOF-MS acquisition was done at declustering potential as $80 \mathrm{~V}$ with $20 \mathrm{~V}$ as spread and using $10 \mathrm{~V}$ collision energy. To perform TOF-MS-MS analysis, $50 \mathrm{~V}$ collision energy with $20 \mathrm{~V}$ spread was used. As the mass acquisition was carried out in positive mode, the observed masses correspond to the mass of the $\mathrm{H}^{+}$-adduct of the parent molecule. The presence of a specific species/molecule was confirmed by the presence of precursor mass within 5 ppm error range as well as its fragmentation pattern.

\section{TLC (thin layer chromatography) of POPC}

TLC analysis for evaluating the chemical stability of POPC molecules was performed using TLC Silica gel $60 \mathrm{~F}_{254}$ (Merck, EMD Millipore Corporation). A mixture of chloroform, methanol, and water in 65:25:4 was used as the mobile phase. The TLC chamber (Latch-lid TLC developing chambers for $10 \times 10 \mathrm{~cm}$ plates, Sigma-Aldrich) was lined with filter paper and equilibrated with the solvent system before use. The TLC plates (dimension $5 \times$ $10 \mathrm{~cm}$ ) were pre-run with the mobile phase in order to eliminate interference coming from any intrinsic contaminant. It was then dried, and $6 \mu \mathrm{L}$ of each sample withdrawn at different $\mathrm{DH}-\mathrm{RH}$ cycles (cycle 0, cycle 4, cycle 10, cycle 20, and cycle 30 in lanes b, c, $d, e$, and $f$, respectively) along with POPC as a control (lane a), was spotted $0.8 \mathrm{~cm}$ apart to each other and $2 \mathrm{~cm}$ above the bottom edge of TLC plate. The dried TLC plates were then chromatographed in the equilibrated chamber. Following the chromatography, the TLC plates were dried and kept in the presaturated tank containing iodine vapors. The plates were then immediately scanned on a Syngene G-Box Chemi-XRQ gel documentation system (Syngene).

\section{ACKNOWLEDGMENTS}

The authors wish to acknowledge the Mass spectrometry facility (cofunded by DST-FIST and IISER Pune) and the Microscopy facility at IISER Pune. S.R. acknowledges the Department of Biotechnology, Ministry of Science and Technology, Government of India (BT/PR19201/BRB/10/1532/2016) for extramural funding. S.D. acknowledges the research fellowship received from CSIR, Government of India. S.S. acknowledges the research fellowship received from IISER Pune. We are grateful to Dr. Niraja Bapat and Mr. Manesh P. Joshi for their critical input on the manuscript.

Received December 11, 2019; accepted March 19, 2020.

\section{REFERENCES}

Becker S, Schneider C, Dejmek M, Carell T, Okamura H, Crisp A, Amatov T, Dejmek M, Carell T. 2018. Wet-dry cycles enable the parallel origin of canonical and non-canonical nucleosides by 
continuous synthesis. Nat Commun 9: 163. doi:10.1038/s41467017-02639-1

Becker S, Feldmann J, Wiedemann S, Okamura H, Schneider C, Iwan K, Crisp A, Rossa M, Amatov T, Carell T. 2019. Unified prebiotically plausible synthesis of pyrimidine and purine RNA ribonucleotides. Science 366: 76-82. doi:10.1126/science.aax2747

Black RA, Blosser MC, Stottrup BL, Tavakley R, Deamer DW, Keller SL, Boxer SG. 2013. Nucleobases bind to and stabilize aggregates of a prebiotic amphiphile, providing a viable mechanism for the emergence of protocells. Proc Natl Acad Sci 110: 13272-13276. doi:10 $.1073 /$ pnas.1300963110

Blain JC, Szostak JW. 2014. Progress toward synthetic cells. Annu Rev Biochem 83: 615-640. doi:10.1146/annurev-biochem-080411124036

Blaskó A, Bruice TC. 1999. Recent studies of nucleophilic, generalacid, and metal ion catalysis of phosphate diester hydrolysis. Acc Chem Res 32: 475-484. doi:10.1021/ar980060y

Budin I, Szostak JW. 2011. Physical effects underlying the transition from primitive to modern cell membranes. Proc Natl Acad Sci 108: 5249-5254. doi:10.1073/pnas. 1100498108

Chen IA, Walde P. 2010. From self-assembled vesicles to protocells. Cold Spring Harb Perspect Biol 2: a002170. doi:10.1101/cshper spect.a002170

Chen IA, Salehi-Ashtiani K, Szostak JW. 2005. RNA catalysis in model protocell vesicles. J Am Chem Soc 127: 13213-13219. doi:10 $.1021 / \mathrm{ja0} 01784 \mathrm{p}$

Costanzo G, Saladino R, Crestini C, Ciciriello F, Di Mauro E. 2007. Nucleoside phosphorylation by phosphate minerals. J Biol Chem 282: 16729-16735. doi:10.1074/jbc.M611346200

Costanzo G, Saladino R, Botta G, Giorgi A, Scipioni A, Pino S, Di Mauro E. 2012. Generation of RNA molecules by a base-catalysed click- like reaction. ChemBioChem 13: 999-1008. doi:10.1002/ cbic. 201200068

Costanzo G, Pino S, Timperio AM, Šponer JE, Šooner J, Nováková O, Šedo O, Zdráhal Z, Di Mauro E. 2016. Non-enzymatic oligomerization of $3^{\prime}, 5^{\prime}$ cyclic AMP. PLoS One 11: e0165723. doi:10.1371/ journal.pone.0165723

Costanzo G, Giorgi A, Scipioni A, Timperio AM, Mancone C, Tripodi M, Kapralov M, Krasavin E, Kruse H, Šponer J, et al. 2017. Nonenzymatic oligomerization of $3^{\prime}, 5^{\prime}$-cyclic CMP induced by proton and UV irradiation hints at a nonfastidious origin of RNA. ChemBioChem 18: 1535-1543. doi:10.1002/cbic .201700122

Dalai P, Ustriyana P, Sahai N. 2018. Aqueous magnesium as an environmental selection pressure in the evolution of phospholipid membranes on early earth. Geochim Cosmochim Acta 223: 216-228. doi:10.1016/j.gca.2017.11.034

Damer B, Deamer D. 2015. Coupled phases and combinatorial selection in fluctuating hydrothermal pools: a scenario to guide experimental approaches to the origin of cellular life. Life (Basel) 5: 872887. doi:10.3390/life5010872

Deamer DW, Barchfeld GL. 1982. Encapsulation of macromolecules by lipid vesicles under simulated prebiotic conditions. J Mol Evol 18: 203-206. doi:10.1007/BF01733047

Deamer D, Singaram S, Rajamani S, Kompanichenko V, Guggenheim S. 2006. Self-assembly processes in the prebiotic environment. Philos Trans R Soc Lond B Biol Sci 361: 1809-1818. doi:10.1098/rstb.2006.1905

DeGuzman V, Vercoutere W, Shenasa H, Deamer D. 2014. Generation of oligonucleotides under hydrothermal conditions by non-enzymatic polymerization. J Mol Evol 78: 251-262. doi:10.1007/ s00239-014-9623-2

Ferris JP. 2005. Mineral calalysis and prebiotic synthesis : montmorillonite-catalysed formation of RNA. Elements 1: 145-149. doi:10 .2113/gselements.1.3.145
Forsythe JG, Yu S-S, Mamajanov I, Grover MA, Krishnamurthy R, Fernández FM, Hud N V. 2015. Ester-mediated amide bond formation driven by wet-dry cycles: a possible path to polypeptides on the prebiotic earth. Angew Chem Int Ed 54: 9871-9875. doi:10.1002/anie.201503792

Gerlt JA, Westheimer PH, Sturtevant JH. 1974. The enthalpies of hydrolysis of acyclic, monocyclic, and glycoside cyclic phosphate diesters. J Biol Chem 250: 5059-5067.

Gilbert W. 1986. Origin of life: the RNA world. Nature 319: 618. doi:10.1038/319618a0

Giovanna C, Pino S, Ciciriello F, Di Mauro E. 2009. Generation of long RNA chains in water. J Biol Chem 284: 33206-33216. doi:10 .1074/jbc.M109.041905

Higgs PG. 2016. The effect of limited diffusion and wet-dry cycling on reversible polymerization reactions: implications for prebiotic synthesis of nucleic acids. Life (Basel) 6: E24. doi:10.3390/life6020024

Jin L, Kamat NP, Jena S, Szostak JW. 2018. Fatty acid/phospholipid blended membranes: a potential intermediate state in protocellular evolution. Small 14: e1704077. doi:10.1002/smll.201704077

Joshi PC, Aldersley MF, Zagorevskii D V, Ferris JP. 2012. A nucleotide dimer synthesis without protecting groups using montmorillonite as catalyst. Nucleosides Nucleotides Nucleic Acids 31: 536-566. doi:10.1080/15257770.2012.701787

Joshi M, Samanta A, Tripathy G, Rajamani S. 2017. Formation and stability of prebiotically relevant vesicular systems in terrestrial geothermal environments. Life (Basel) 7: E51. doi:10.3390/ life 7040051

Kaddour H, Gerislioglu S, Dalai P, Miyoshi T, Wesdemiotis C, Sahai N. 2018. Nonenzymatic RNA oligomerization at the mineral-water interface: an insight into the adsorption-polymerization relationship. J Phys Chem C 122: 29386-29397. doi:10.1021/acs.jpcc .8b10288

Kaiser A, Richert C. 2013. Nucleotide-based copying of nucleic acid sequences without enzymes. J Org Chem 78: 793-799. doi:10 .1021/jo3025779

Khorana HG, Tener GM, Wright RS, Moffatt JG. 1957. Cyclic phosphates. III. Some general observations on the formation and properties of five-, six- and seven-membered cyclic phosphate esters. J Am Chem Soc 79: 430-436. doi:10.1021/ja01559a054

Lailach GE, Thompson TD, Brindley GW. 1968. Absorption of pyrimidines, purines, and nucleosides by $\mathrm{Co}-, \mathrm{Ni}-, \mathrm{Cu}-$, and $\mathrm{Fe}$ (III)-montmorillonite (clay-organic studies XIII). Clays Clay Miner 16: 295-301. doi:10.1346/CCMN.1968.0160406

Li L, Prywes N, Tam CP, Oflaherty DK, Lelyveld VS, Izgu EC, Pal A, Szostak JW, O'Flaherty DK, Lelyveld VS, et al. 2017. Enhanced nonenzymatic RNA copying with 2-aminoimidazole activated nucleotides. J Am Chem Soc 139: 1810-1813. doi:10.1021/jacs $.6 \mathrm{~b} 13148$

Lohrmann R, Orgel LE. 1973. Prebiotic activation processes. Nature 244: 418-420. doi:10.1038/244418a0

Luisi PL, Walde P, Oberholzer T. 1999. Lipid vesicles as possible intermediates in the origin of life. Curr Opin Colloid Interface Sci 4: 3339. doi:10.1016/S1359-0294(99)00012-6

Majerfeld I, Puthenvedu D, Yarus M. 2016. Cross-backbone templating; ribodinucleotides made on poly(C). RNA 397-407. doi:10 $.1261 /$ rna.054866.115

Mamajanov I, Macdonald PJ, Ying J, Duncanson DM, Dowdy GR, Walker CA, Engelhart AE, Fernández FM, Grover MA, Hud NV, et al. 2014. Ester formation and hydrolysis during wet-dry cycles: generation of far-from-equilibrium polymers in a model prebiotic reaction. Macromolecules 47: 1334-1343. doi:10.1021/ ma402256d

Mansy SS. 2009. Model protocells from single-chain lipids. Int J Mol Sci 10: 835-843. doi:10.3390/ijms10030835 
Monnard P-A, Walde P. 2015. Current ideas about prebiological compartmentalization. Life (Basel) 5: 1239-1263. doi:10.3390/ life5021239

Mungi CV, Rajamani S, Mungi CV, Rajamani S. 2015. Characterization of RNA-like oligomers from lipid-assisted nonenzymatic synthesis: implications for origin of informational molecules on early earth. Life (Basel) 5: 65-84. doi:10.3390/life5010065

O'Flaherty DK, Kamat NP, Mirza FN, Li L, Prywes N, Szostak JW. 2018. Copying of mixed-sequence RNA templates inside model protocells. J Am Chem Soc 140: 5171-5178. doi:10.1021/jacs.8b00639

Pandey S, Clarke J, Nema P, Bonaccorsi R, Som S, Sharma M, Phartiyal B, Rajamani S, Mogul R, Martin-Torres J, et al. 2020. Ladakh: diverse, high-altitude extreme environments for off-earth analogue and astrobiology research. Int J Astrobiol 19: 78-98. doi:10.1017/S1473550419000119

Pino S, Ciciriello F, Costanzo G, Di Mauro E. 2008. Nonenzymatic RNA ligation in water. J Biol Chem 283: 36494-36503. doi:10.1074/jbc .M805333200

Powner MW, Gerland B, Sutherland JD. 2009. Synthesis of activated pyrimidine ribonucleotides in prebiotically plausible conditions. Nature 459: 239-242. doi:10.1038/nature08013

Powner MW, Sutherland JD, Szostak JW. 2010. Chemoselective multicomponent one-pot assembly of purine precursors in water. J Am Chem Soc 132: 16677-16688. doi:10.1021/ja108197s

Puthenvedu D, Janas T, Majerfeld I, Yarus M. 2015. Poly(U) RNA-templated synthesis of AppA. RNA 21: 1818-1825. doi:10.1261/rna .052696 .115

Puthenvedu D, Majerfeld I, Yarus M. 2018. Non-Watson-Crick RNA synthesis suited to origin functions. RNA 24: 90-97. doi:10 $.1261 /$ rna.063974.117

Rajamani S, Vlassov A, Benner S, Coombs A, Olasagasti F, Deamer D. 2008. Lipid-assisted synthesis of RNA-like polymers from mononucleotides. Orig Life Evol Biosph 38: 57-74. doi:10.1007/s11084007-9113-2

Ross D, Deamer D. 2016. Dry/wet cycling and the thermodynamics and kinetics of prebiotic polymer synthesis. Life (Basel) 6: 28. doi:10.3390/life6030028
Saladino R, Botta G, Pino S, Costanzo G, Di Mauro E. 2012. Genetics first or metabolism first? The formamide clue. Chem Soc Rev 41: 5526-5565. doi:10.1039/c2cs35066a

Sarkar S, Dagar S, Verma A, Rajamani S. 2020. Compositional heterogeneity confers selective advantage to model protocellular membranes during the origins of cellular life. Sci Rep 10: 4483. doi:10 .1038/s41598-020-61372-w

Sasidharan S, Pochinda S, Naja Elgaard-Jørgensen P, Rajamani S, Khandelia H, Raghunathan VA. 2019. Interaction of the mononucleotide UMP with a fluid phospholipid bilayer. Soft Matter 15: 8129-8136. doi:10.1039/C9SM01257E

Suárez-Marina I, Abul-Haija YM, Turk-Macleod R, Gromski PS, Cooper GJT, Olivé AO, Colón-Santos S, Cronin L. 2019. Integrated synthesis of nucleotide and nucleosides influenced by amino acids. Commun Chem 2: 28. doi:10.1038/s42004-0190130-7

Tam CP, Fahrenbach AC, Björkbom A, Prywes N, Izgu EC, Szostak JW. 2017. Downstream oligonucleotides strongly enhance the affinity of GMP to RNA primer-template complexes. J Am Chem Soc 139: 571-574. doi:10.1021/jacs.6b09760

Tapiero CM, Nagyvary J. 1971. Prebiotic formation of cytidine nucleotides. Nature 231: 42-43. doi:10.1038/231042a0

Toppozini L, Dies H, Deamer DW, Rheinstädter MC. 2013. Adenosine monophosphate forms ordered arrays in multilamellar lipid matrices: insights into assembly of nucleic acid for primitive life. PLoS One 8: e62810. doi:10.1371/journal.pone.0062810

Usher DA, McHale AH. 1976. Hydrolytic stability of helical RNA: a selective advantage for the natural 3',5'-bond. Proc Natl Acad Sci 73: 1149-1153. doi:10.1073/pnas.73.4.1149

Verlander MS, Orgel LE. 1974. Analysis of high molecular-weight material from polymerization of adenosine cyclic $2^{\prime}, 3^{\prime}$-phosphate. $J$ Mol Evol 3: 115-120. doi:10.1007/BF01796557

Verlander MS, Lohrmann R, Orgel LE. 1973. Catalysts for the self-polymerization of adenosine cyclic 2', $3^{\prime}$-phosphate. J Mol Evol 2: 303-316. doi:10.1007/BF01654098

Yi R, Hongo Y, Fahrenbach AC. 2018. Synthesis of imidazole-activated ribonucleotides using cyanogen chloride. Chem Commun 54: 511-514. doi:10.1039/C7CC08489G 

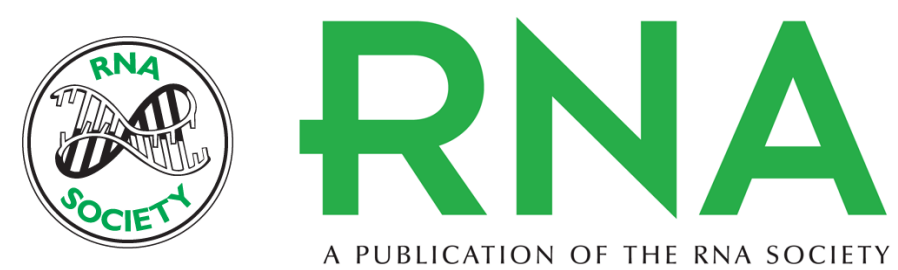

\title{
Geochemical influences on nonenzymatic oligomerization of prebiotically relevant cyclic nucleotides
}

Shikha Dagar, Susovan Sarkar and Sudha Rajamani

RNA 2020 26: 756-769 originally published online March 23, 2020

Access the most recent version at doi:10.1261/rna.074302.119

\begin{abstract}
References This article cites 58 articles, 12 of which can be accessed free at: http://rnajournal.cshlp.org/content/26/6/756.full.html\#ref-list-1

Creative This article is distributed exclusively by the RNA Society for the first 12 months after the Commons full-issue publication date (see http://rnajournal.cshlp.org/site/misc/terms.xhtml). After 12 License months, it is available under a Creative Commons License (Attribution-NonCommercial 4.0 International), as described at http://creativecommons.org/licenses/by-nc/4.0/.
\end{abstract}

Email Alerting Receive free email alerts when new articles cite this article - sign up in the box at the Service top right corner of the article or click here. 